\title{
School Principals' Opinions on Data-based School Management: A Case Study
}

\author{
Ömer ÖZ* \\ Educational Administration, Hacettepe University, Ankara, Turkey \\ ORCID: 0000-0002-9371-8470
}

\author{
Gökhan ARASTAMAN \\ Educational Administration, Hacettepe University, Ankara, Turkey \\ ORCID: 0000-0002-4713-8643
}

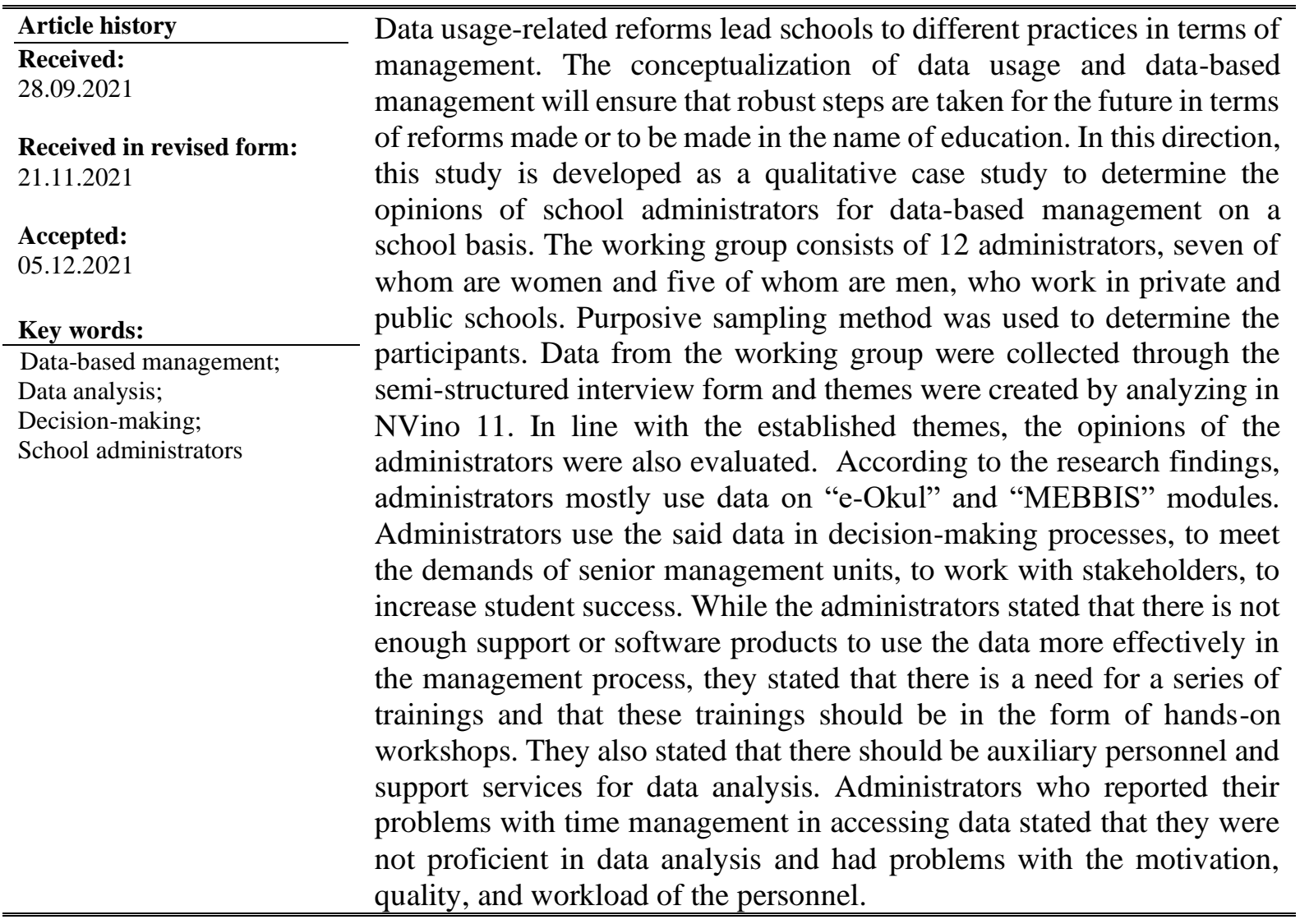

\section{Introduction}

Technology-related developments bring with it digitalization. According to Gobble (2018), digitalization is a simple process of converting analogue information to digital.

\footnotetext{
* Correspondency: omeroz84@gmail.com
} 
Digitalization refers to the use of digital technology to create value in new ways. It can be said that digitalization in education has started with the use of information and communication technologies in educational environments. Personal information of students and employees in Bir educational institution, videos, audio recordings, text files, e-mails used in the learning environment, social media shares, etc. are stored electronically (Özen, Kartal and Emre, 2017, p.106; Ayy1ldiz, 2020). Schools have a wide range of educational data, both from internal sources and from external sources. From this data, the data held on student grades, absence information, student portfolios, achievement assessments, course attendance status, loans, learning management systems are increasing day by day (Rasheed, 2018). Therefore, determining what kind of data should be used to determine variables such as student's behavior, exam results and the development of each student, educational needs and administrative data becomes an important issue for the school administration. Since information is one of the most important tools of management, it can be said that managers who hold information, benefit from data in the decision-making process, and do not act only with estimations and intuitions will be more effective in management.

Although students' learning results come to mind when it comes to data in schools, information such as demographic information, observations, surveys, school programs, family information, absenteeism are also included in the data (Turan, 2019; Matters, 2006). The decision-making process using this data requires educators to knowhow to analyze, interpret and use data so that they can make informed decisions in all areas of education, from professional development to student learning. Different studies on data-based school management have also been conducted in the international arena, which strengthens these inferences for school administrators (Reeves and Burt, 2006; Levin and Datnow, 2012; Bowers, Shoho and Barnett, 2014). When the studies are examined, it can be said that an administrator sets out a regular prescription for how a school should shape its focus (Marzano, Waters, \& McNulty, 2005). Studies conducted in this direction indicate that school administrators should shape the information shared in the learning and teaching processes in the behavior of collecting and interpreting data (Picciano, 2006). If we read between the lines, the importance of systematically collecting, analyzing and interpreting and presenting data sources has become clearer. Administrators in the information age need to be knowledge-driven, committed to shared leadership, and relentless in continuous improvement (Reeves and Burt, 2006). It can be said that this study will contribute to the international field in terms of common denominators in terms of explaining which data and how school administrators use, the support they receive and the factors affecting data use.

Data usage and data-based decision-making are of great importance in management in educational organizations. In fact, the figures, visuals, plans, books, etc. that administrators and teachers have long determined in both management processes and learning processes are databased decisions (Yenel, 2013). The task of decision-making in education is also very important due to the need to improve the quality of interaction between teaching and learning resources (Ayeni, 2018). Administrators have always had some kind of "data" when making decisions. Having the right data can directly or indirectly affect both management and learning and teaching processes. According to Simon (1997), in addition to some mid-level management decision areas where linear programming (operations research) and expert systems (from artificial intelligence) are widely used as an important form of decision-making, computers have modestly changed executive decision-making processes and the structures of organizations. Technological equipment, algorithms and software stabilize their presence in the structures of organizations to help administrators with their work in the decision-making process (Durnal1, 2020, p.42). In line with the "School-Based Data-based Management" action plan specified in the 2023 Education Vision (MoNE, 2019) of Ministry of National Education 
(MoNE). It is a great importance to determine what data administrators use, how they use, receive and access data in school administration. In this context, the fact that the studies carried out in literature are mostly theoretical and the studies carried out with the administrators through the data increase the importance of this study.

\section{Data-based Management}

Data-based management is about creating a culture based on tools, skills, and most importantly, data. According to Yenel (2019), the test results of the students and the indicators related to the performance of the teachers for those subjects appear as a type of data. The use of this data in management requires the creation of a kind of culture. According to Doyle (2003), teachers and administrators will welcome this when data becomes useful and mundane in the classroom, and data quality will also improve. In this context, it can be said that the main purpose of databased management is to use the school's data to improve the decision-making processes in the school.

The 2023 Education Vision Document indicates that the ministry attaches importance to data by stating that it will move to data-based management on a school basis. Accordingly, one of the applications planned to be realized in the 2023 Education vision for data-based management is an online platform where school development plans can be monitored. In addition, it is among the actions determined that a geographical information system will be established to determine the capacities of schools in the planning of educational resources. At the point of cooperation with parents, which is one of the most important stakeholders of education, MEB plans to establish a new platform on the Parent Information System and to ensure interaction between teachers, parents, and schools on this platform. It was stated that the students who need support will be determined by data analysis and the necessary actions will be included in the development plans on a school basis. In this context, it can be said that MEB's data-based management plan is based on school development, improving student success, and increasing interaction with parents.

The purpose of analyzing data is important in data-based management. The main purpose of analyzing data for a teacher is to improve the learning of one or more students. The headmaster analyzes the data to manage the school for its purposes. These objectives differ further in senior management; For a policymaker, the goal is to know the impact of some policies (Allen, 2005). In addition to the purpose of analyzing the data, the ability to analyze the data is of great importance. McNamara and Thompson (1996) proposed an alternative strategy to improve data analysis skills in school administrators, highlighting data analysis as a discovery process. This model focuses on how to teach data analysis skills in teacher training programs, while the following guidelines include:

- Emphasizing data analysis

- Using real-world data

- Focus on descriptive statistics

- Using accurate descriptions

- Learning exploratory data

- Using graphic displays

- Reporting outliers

According to Earl and Katz (2006), in a data-rich world, school administrators should develop a mental interrogation habit, be data literate, and create a culture of inquiry. Therefore, these 
investments in data creation will allow for increased use of evidence by decision makers to allocate resources, plan programs and evaluate results.

\section{Data-based Decision Making}

Lai and Schildkamp (2013, p.10) refer to the definition of data in the context of education as "information systematically collected and edited to represent certain aspects of schools". This data covers many quantitative and qualitative data that teachers and school administrators need to make decisions (Lai and Schildkamp, 2013; Wayman, Jimerson and Cho, 2012). If this data is used by school staff to guide decisions such as school development or teaching purposes, it is called data-based decision-making or, in short, data usage.

Data-based decision-making refers to the process of deciding on a data-based action plan. It is an integral part of complex management processes such as decision making, academic planning and policy making in a school organization. Lunenburg and Ornstein (2013) stated that decision-making is involved in all processes and that the decisions taken will affect all processes and therefore the management of the organization. The basis of the definition of databased decision-making is the assumption of a rational process based on data. The meaning of this process depends on the active use of information and communication technologies in education and the fact that organizational culture is based on data (Leary, 2015).

It is important for the school to use information about the student's learning, development, and progress to improve school and classroom practices. More than 10 studies have shown that effective data use improves student achievement (Campbell \& Levin, 2009; Carlson, Borman, and Robinson, 2011; Van Geel, Keuning, Visscher and Fox, 2016). At this point, data can be used for feedback in decision-making by providing information about the gap between students' learning outcomes and the teacher's goals.

\section{Purpose of Research}

The aim of this study is to determine the opinions of school administrators for databased management on a school-by-school basis. In this context, the following questions regarding data-based management were sought in the research:

(1) What kind of data do participant administrators use in school administration?

(2) How do administrators use this data?

(3) What kind of support is there/should there/ be to help with the use of data in school?

(4) What are the factors affecting data usage in the decision-making process?

The opinions given to these questions were discussed in detail in the context of the opinions of school administrators for data-based management on that basis.

\section{Method}

This study is a case study that is a qualitative research method for determining the opinions of school administrators for data-based management on a school-by-school basis. The case study is a qualitative approach in which the researcher collects detailed and in-depth information through real life, a limited current situation, or multiple sources of information over a given time and presents a situation description or situation themes (Creswell, 2018, p. 97). Case study is a comprehensive description and analysis of a limited system (Merriam and Tisdell, 2016, p. 37). In this context, the opinions of school administrators regarding data-based management have been tried to be determined. 


\section{Participants}

The working group of the study consists of 12 school administrators who work in the private sector and the public sector. Purposive sampling method was used to determine the participants. Purposeful sampling assumes that the researcher chooses the best example he can learn to gain insight, understand, and explore insight (Meriam and Tisdell, 2016, p. 96). According to Patton (2015), the purposeful sample lies in the selection of information-rich situations for in-depth study. Information-rich situations are subjects where important information can be obtained for the purpose of the research. In this context, the participants of the study were selected from among school administrators who are experienced in management. Information about the gender, average age, seniority, seniority in management, level of education, Institution of employment, type of institution and their role in the school are shown in Table 1.

Table 1. Demographics of School Administrators

\begin{tabular}{|c|c|c|}
\hline \multicolumn{2}{|c|}{ Demographics of School Administrators } & \multirow{2}{*}{$\begin{array}{l}\mathbf{f} \\
7\end{array}$} \\
\hline Gender & Female & \\
\hline & Male & 5 \\
\hline Average age & & 37,54 \\
\hline \multirow[t]{4}{*}{ Seniority } & 1-6 Years & \\
\hline & 7-10 Years & 1 \\
\hline & 11-20 Years & 10 \\
\hline & 21 Years and Above & 1 \\
\hline \multirow[t]{4}{*}{ Seniority in Management } & 1-6 Years & 6 \\
\hline & 7-10 Years & 5 \\
\hline & 11-20 Years & 1 \\
\hline & 21 Years and Above & \\
\hline \multirow[t]{3}{*}{ Educational Background } & License & 6 \\
\hline & Master & 5 \\
\hline & Doctorate & 1 \\
\hline \multirow[t]{2}{*}{ Institution of employment } & Public & 10 \\
\hline & Private & 2 \\
\hline \multirow[t]{4}{*}{ Type of institution } & Kindergarten & 1 \\
\hline & Primary school & 7 \\
\hline & Secondary school & 1 \\
\hline & High school & 2 \\
\hline \multirow[t]{2}{*}{ Role at School } & Vice-Principal & 5 \\
\hline & Principal & 7 \\
\hline
\end{tabular}

As shown in Table 1, the participants consisted of 7 females and 5 males. The average age of the participants was 3.54. The seniority of the school administrators is in the majority between 11-20 years (10 people) and there are 1 school administrators between 7-10 years and 1 school 
administrator for 21 years or more. There are 6 school administrators between 1-6 years, 5 between 7-10 years and 1 school administrator between 11-20 years. The level of education of school administrators is mostly at undergraduate level, there are 5 people in master's degree and 1 person at doctoral level. Some of the administrators working in the public sector (10) and others (2) working at private sector. There are 7 people who work in kindergarten, 7 in elementary school, 1 in middle school and 2 in high school. 7 of the participated in the study are principals and 5 are vice-principals.

\section{Data Collection Tools}

Observation, interviews, and analyses are important activities of qualitative research (Meriam and Tisdell, 2016, p. 2). In this study, research data were collected with semistructured interview technique. In the process of determining the interview questions, literature was first reviewed, and then expert opinion was applied. In accordance with the feedback received after the expert opinion, the final version of the four-question semi-structured interview form has been finalized.

\section{Analysis of Data}

School administrators are coded as A1, A2, A3, A4, etc. in the order of the interview. Interview forms were given to volunteer school administrators who wanted to participate in the study and their answers were recorded one by one. The evaluating of the received records by analyzing and grouping is the work. In accordance with the permissions of the interviews with the school administrators, the audio recordings were recorded, and the audio recordings transferred to the computer environment and transcribed. Analysis for the case study depends on making a detailed description of the situation and environment (Creswell, 2018). In this context, after the s es registration data was written, the data was analyzed through the NVivo 11. NVivo is a software with features such as character-based encoding, rich text features and multimedia functions that are very important for qualitative data management (Zamawe, 2015). Accordingly, the researcher transferred the written audio recordings to the NVivo, the data was encoded, and themes were created in accordance with the interview questions. According to Patton (2015), the researcher who analyzed the content in the qualitative research should decide how something is formed to shape a topic, what constitutes a theme, what to name and how to express the result to be extracted from the case studies. The answers given by the school administrators to each question were interpreted in the context of the themes in terms of their similarities, and some answers to the questions were given exactly. Expert opinions have been consulted on the creation of themes and the suitability of the coded content to the themes.

\section{Reliability of Research}

In qualitative research, triangulation is used to increase validity and reliability. Triangulation is the diversification of data sources, data collection method and researcher to verify the findings (Meriam and Tisdell, 2016, p. 259). In order to confirm the findings reached in this study, researcher diversification from the diversification method specified by Patton (2015) was used. In the study, apart from the researchers, another educational science expert participated in the analysis, so that the researcher was diversified. The volunteering of the participants to participate in the study is an important condition for the validity and reliability of the research (Yıldırım and Şimşek, 2011). In order to increase the validity of the study, the selection of the experts was based on voluntariness, and it was stated that their names would be kept confidential and would not be disclosed in any way so that they could answer the questions sincerely. In addition, data were collected through face-to-face interviews with experts. The 
opinions of three experts were used for the interview form in which the data were collected. The opinions of the participants were conveyed as in the findings section.

\section{Results}

\section{School Administrators' Views on What Kind of Data Administrators Use in School Administration}

The themes determined in line with the opinions of those administrators regarding what kind of data they use in school administration are shown in Figure 1.

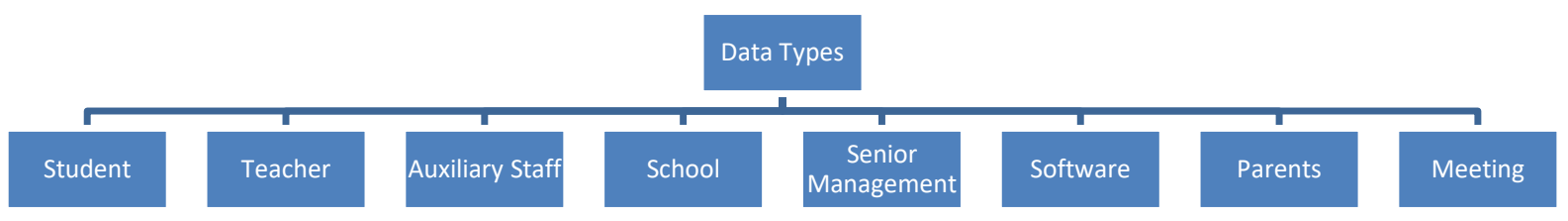

Figure 1. School administrators' views on what kind of data administrators use in school management

When the opinions of the school administrators are evaluated in general, the above-mentioned themes are created. Accordingly, some school administrators have made the following assessments:

A1: "Within our Ministry, applications such as MEBBIS, e-Okul, eba, dys, e-rehberlik, eyaygin, e-kurs, tefbis, e-library, transport student module, kbs, ekap, open education secondary school - high school are among the most used data sources by school administrators. However, it can be stated that the most used of these is the e-Okul with the data of the students and the MEBBIS system, where the data of teachers and administrators is located, and the business procedures are carried out."

A4: "Systemic data E-Okul, Meis, MEBBIS, Tefbis and so on. Data obtained by in-school meetings, interviews, etc. IKS teacher student parent surveys applied at the end of the 2nd semester; surveys applied when strategic planning is carried out. Central examinations, course grades, documents received, social influences module, books read, development report, absence status, data obtained from the graphs and reports prepared on the socio-cultural and economic situation. Informal data, data transmitted verbally or based on observation. Data obtained through social media tools and school websites."

A7: "Generally e-Okul and MEBBIS data, parent and student feedback, teachers' board, meetings information."

A8: "We use data linked to the survey, statistical data, data from the ministry and provincial national education."

In line with the opinions of the school administrators and the established themes, the opinions about what kind of data the administrators use in the school administration are combined with the data of the students. School administrators stated that they collected data such as attendance, grades, passing class, class repetition, documents received, health, student population information, behavior, social activity, report, number of books read, success status, special education requirement for students. School administrators stated that they collected data for 
teachers regarding employment, learning status, seniority, attendance and absence, courses taken, and reported that they also used data obtained through observation, interview, and verbal means in meetings. School administrators who reported that the data about the auxiliary staff were also used as data in the school stated that they benefited from e-Okul (School Management Information System), MEBBIS (Ministry of National Education Information Systems), DYS (File Management System), KBS (Public Expenditure and Accounting Information System), social media accounts, EBA (Education information Network), e-rehberlik (E-guidance and counselling decision support system), e-yaygin (Non-formal Education Information System), e-kurs (Supporting and Training Courses), tefbis (Education Financing and Education Expenditures Information Management System in Turkey), e-kütüphane (e-Library), transport student module, EKAP (Electronic Public Procurement Platform), open education operations software offered by the ministry in collecting this data. In addition, the ministry stated that they collected data about the school from the senior management such as provincial/district national education. School administrators stated that they used the records and documents kept in the school as data.

\section{School Administrators' Views on How Administrators Use Data}

The themes determined in line with the views of those administrators regarding how administrators use the data are shown in Figure 2.

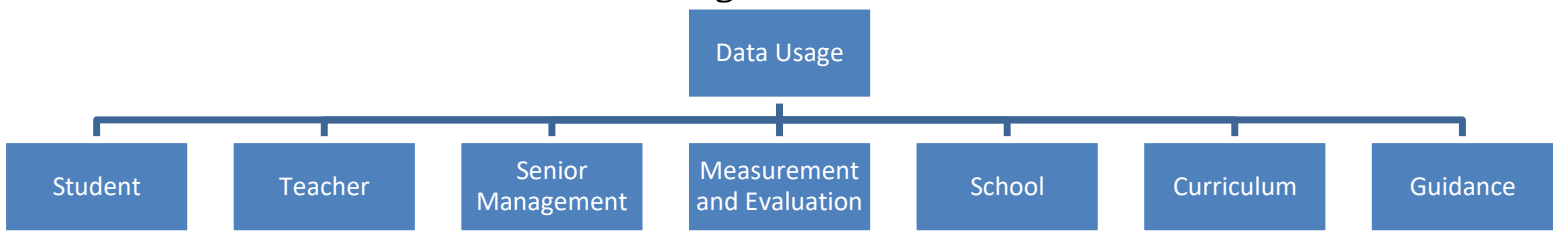

Figure 2: School administrators' views on how administrators use data

When the opinions of the school administrators are evaluated in general, the above-mentioned themes are created. Accordingly, some school administrators have made the following assessments:

A11: "This data is used to create classrooms, to identify teachers in classrooms, to assign teachers or students for schoolwork, to keep the school's memory when information is requested from the higher authorities."

A12: "Measurement of student levels, observance of school population, distribution of boys and girls, absence-absence status, GPAs."

A4: "The effectiveness of the data is looked at when creating action that can be applied for the benefit of the institution. Qualified data is used, and if the data is considered unqualified or biased, it can be ignored. Numerical data showing success, attendance status, social studies, etc. are used to create new targets in strategic planning. Administrators use positive data to create positive perceptions of the environment and stakeholders, that is, the organization is advertised. Existing data can be shared with all stakeholders through meetings and used solution oriented. Data is also used to improve the structure of the institution by comparing it with previous data."

A6: "The progress of the students continues to be monitored in the guidance documents. Official minutes and meeting documents ensure that the current information for that year, which continues within the school, is stored and sheds light on the following years." 


\section{A8: "We often use it for measurement evaluation."}

It can be said that the opinions of school administrators and themes are combined on measuring and evaluating the views of administrators on how they use the data. Accordingly, school administrators use data in activities such as determining the factors affecting grade point averages and measuring the student level. In addition, school administrators who report that they use the data for the purpose of tracking attendance and increasing the reading rate for students also state that teachers use the data for salary, additional course, and success certificate situations. School administrators also use data to track student development in line with guidance activities. School administrators, who also use data for the development of curriculums, use data for strengthening the structure of the school, making solution-oriented studies, strategic planning, creating classrooms, shedding light on the following years, strengthening school memory, organizing class entrance and exit times, planning parent meetings and parent guidance. "Administrators use positive data to create positive perceptions on the environment and stakeholders, that is, the organization is advertised." A4 stated that positive data is used as an advertising tool without attracting the attention of stakeholders. In addition, school administrators stated that they use the data to meet the requests from the ministry, provincial and district national education directorates, and that they collect and use the data to ensure regularity of the work and operation in the institution.

\section{School Administrators' Views on What Kind of Support / Should Be Available to Help with Data Usage in School}

The themes set out in line with the opinions of those administrators regarding what kind of support/should be provided to help administrators use data in school are shown in Figure 3.

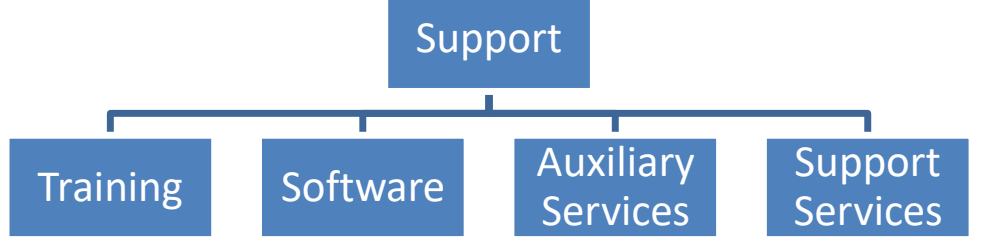

Figure 3. School administrators' views on what kind of support should be available to help with data usage in school

When the opinions of the school administrators are evaluated in general, the above-mentioned themes are created. Accordingly, some school administrators have made the following assessments:

A5: "Easy-to-interface and practical applications are important. We use K12. I'd say it's our data store. Initially, the interface was difficult and incomplete, but it is now better and an upto-date software that is developing itself according to recommendations. We also use Google Drive to create and store corporate memory."

A11: "Absolutely like the information registration system for every school, a software that is more detailed than the current system is needed. Because when administrative staff changes, this data can be difficult to access. All personnel can be trained regarding the data to be used and stored in schools. Thanks to the trainings, the quality is improved by making the data, eclipse patterns and other aspects equal/the same by providing standardization."

A9: "There is no support in kindergarten management to help with the use of data in the school. 
The data sources we use are automatically updated by ministry officials. In the problems encountered, a superior supervisor is informed and expected. This leads to a waste of time. Instead, trainings can be organized, and computer teachers can be assigned to assist school administrators in provincial or district administrations."

A4: "The data warehouse application mentioned in the vision document should be implemented and digital mechanisms should be used to reach comprehensive data as quickly as possible. In this way, repeated correspondence containing the same data between schools and parent institutions and waste of time can be prevented."

In line with the opinions and themes of school administrators, the opinions of administrators on what kind of support/should be available to help with the use of data in school are combined in the software theme. Accordingly, they stated that school administrators use Excel specifically from Office applications in data collection and data analysis. In addition, school administrators who reported that they benefited from e-Okul and MEBBIS in collecting data stated that there should be more useful software as an interface. School administrators who stated that they used the Google Drive application to create school memory, use it as a repository of information and transfer data to later years also stated that the information registration system should be the data warehouse application specified in the MoNE 2023 Education Vision. School administrators stated that there should be hands-on training and workshops in data analysis, while there should also be staff or support services that can help them.

\section{School Administrators' Views on Factors Affecting Data Usage in Administrators' Decision-Making Process}

The themes determined in line with the opinions of those administrators regarding the factors affecting the use of data in the decision-making process are shown in Figure 4.

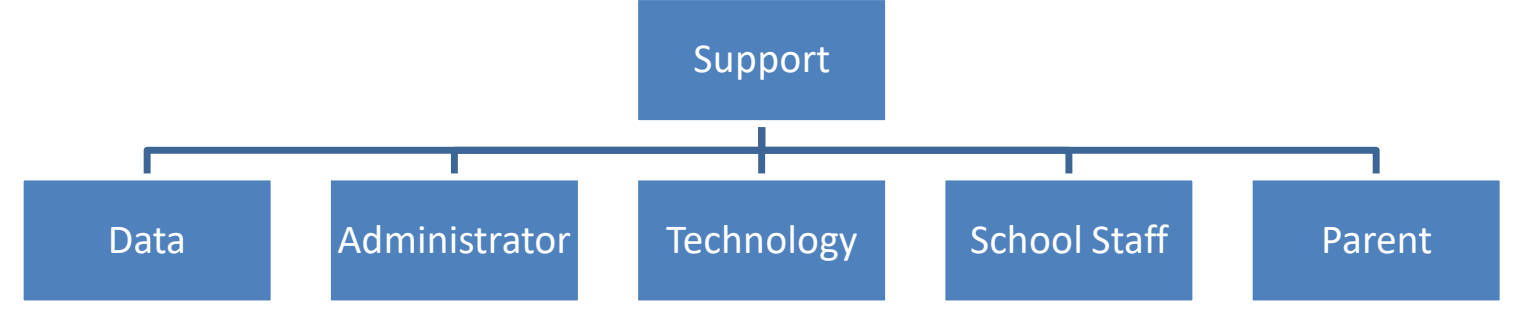

Figure 4. School administrators' opinions on factors affecting data usage in the decisionmaking process

When the opinions of the school administrators are evaluated in general, the above-mentioned themes are created. Accordingly, some school administrators have made the following assessments:

A1: "It is essential that the data is reliable and valid in the decision-making process. In other words, the correct and up-to-date data to be used will have a direct effect on the decisions to be taken in the analysis and interpretations to be made. Another of the elements required for the success of the data-based decision-making process is the diversity of the data collected. The same information obtained from different data sources will make the decision healthier. Again, the quality of the trainings given on how to use the data in the data-based decision-making process will have a positive contribution to data literacy. The decisions taken will be healthier."

A2: "The data sets to which we will collect the data are missing. The inability to know what to 
do in data processing is one of the important factors affecting the data usage of some school principals' tendencies to distort the data."

A6: "Time is one of the factors affecting data usage. Time management is very, very important in management. Considering the historical information data, you are faced with a lot of time when you need to make quick decisions. However, to be up-to-date and accessible, digital platforms should be aware of digital platforms in every environment and work with applications accordingly."

A7: "Insufficient data, reluctance to access data, time shortage, lack of personnel to provide data, inadequate staff, reliability of the data source"

In line with the opinions of school administrators and themes, the opinions of administrators on the factors affecting data usage in the decision-making process are combined in the theme of data reliability and time management. School administrators have stated that data usage is mostly influenced by time management in decision-making and that they do not spend enough time. In addition, administrators emphasized that they do not know enough about data processing, that there is little understanding of decision-making management, and that continuous change of administrators is effective. They have reported that the reliability, diversity, access to data, quality and inadequate data are the most important factors influencing data usage in the decision-making process. Technology literacy in data analysis, data collection tool, interface design of software and lack of quality of reports from applications were also considered as factors affecting data usage in the decision-making process. In addition, school administrators stated that the quality, motivation, and workload of school staff is important, while parents' level of education is inadequate in collecting data.

\section{Conclusion and Discussion}

In this study, what kind of data school administrators use in school administration, how they use this data, what kind of services are or should be available in the school to help use this data, and what factors affect data usage in the decision-making process are evaluated in line with the opinions of school administrators.

It is one of the results that school administrators mostly use data about students in administration. Examples include classroom repetition, special educational needs, enrollment deferral, success status, passing class, student grades, awards, documents, student population information, health status, behavioral evaluation, social activity, guidance studies, graphs, reports, absence status, number of books read. Yibrie Ahmed (2019) states that some data such as students' learning difficulties and socio-economic status are found in high-performing schools. According to According to Matters (2006), the main subject of data collection is the student and student learning. School administrators also use data on teachers and auxiliary staff. Examples of this data include the way the staff is employed, their education status, seniority, and the training they receive. The job with parents is mostly because they use data for parent information.

The data of the school administrators is one of the results obtained that they use for the purposes of the school. In this context, school administrators use the data to organize parent meetings, parent guidance, course entry and exit, shed light on the following years, create classrooms and branches, make the school strategic plan, solution-oriented management, advertising, and institutional structure. At the school level, data indicators support the quality and allocation of resources and supports available to students (Wohlstette, Datnow and Park, 2008). This data 
can help school administrators track progress over time and look for changes between classes or grades to determine how resources and supports are allocated. Examples of school-level data include student data by class levels, measures to be taken, subgroup data, knowledge about special programs and professional development opportunities (Hough, Byun and Mulfinger, 2018). In addition, administrators use data to track students' attendance and attendance, to determine and increase the reading rate. School administrators, who also use data in the field of guidance on the development of students, are among the results reached that they support the development of the curriculum by using data on issues such as determining the factors affecting their GPA and measuring the student level. According to McGill, Kennedy and Busse (2016), apart from official data, there is a variety of data that can be used to evaluate guidance and counseling outcomes in school settings. For example, data on school attendance, job completion, behavioral advice, and test or homework scores are official data, while guidance services' analysis of school attendance and success can be an example of using alternative data. In addition, better, timely data on student performance can help administrators make better decisions about the cost-effectiveness of certain programs and materials (New, 2016). Stating that they use the data for teacher salary and additional course procedures and reward, the school administrators stated that they analyzed the data to meet the requests from the ministry, provincial and district national education directorates. Competencies such as collecting, storing, analyzing, and presenting these data to users are among the competencies expected from digital school leaders together with digitalization (Öz, 2020).

It is one of the results reached that school administrators use office applications, e-Okul and MEBBIS as helpful support in data usage and analysis. In this context, school administrators who state that there should be software such as information recording system in the process of collecting and analyzing data are among the results reached that they use google drive application for information recording. They are the statements stated by school administrators that there should be necessary and adequate training in data analysis, especially hands-on training, and workshops. It has also been learned that school administrators want to get support from computer teachers on data analysis, and that there should be auxiliary staff at the school. The need for data usage and appropriate technical support for data teams was clearly stated in the study of Huffman and Kalnin (2003). Auxiliary staff to assist school administrators can take part in the execution of analysis plans, as they must first collect data and then create analysis and presentation methods in office applications such as Excel. Appropriate training should be given for the creation of these teams and appropriate technologies should be used (Wayman, Midgley and Stringfield, 2006).

Time management is one of the factors affecting the use of data in the decision-making process of school administrators. Other factors affecting data usage in the decision-making process for administrators are ignorance in data analysis, decision-participating management, and the constant change of administrators. The results obtained in terms of data are the reliability, diversity, access to data, quality of data and insufficient data. The quality of the data should be improved by reviewing the methods used for data collection, processing, and indicator calculation. Using new technologies can help reduce the cost of collection and analysis and reduce the error rate. Since bad data contributes to the design of bad policies, all stakeholders should target the highest quality data possible (UNESCO, 2017). The lack of technological tools to be used in data collection and analysis in schools, the lack of interface design in existing ones and the nature of reporting are among the factors affecting the use of data in the decisionmaking process of school administrators. In this context, the data analysis competencies of the administrators come to the forefront that there should be appropriate and adequate technological facilities in schools. The motivation, workload and nature of the school staff are the factors that 
affect data usage. According to Marsh et al. (2006), our students need access to professional development to support their readiness and skills, technical and interrogation skills, and support from talented individuals to make the data more interpretable. In addition, according to Schildkamp, Poortman, Luyten, and Ebbeler (2016), data use is also affected by school organizational features, collaboration, and user characteristics. Another factor affecting data usage is the level of education of parents.

Within the scope of developing and changing technology and the opportunities it offers, it is expected that schools will use data in the international arena on subjects such as monitoring their performance, observing development, and increasing quality (Shildkamp, 2019). The results show that managers have a key role in using data in the literature (Skalski and Romero, 2011). It can be said that the results of the study support the international literature on databased decision making, since school administrators have similar duties in the international arena and have common goals.

\section{Suggestions}

For administrators, when school, county, and county administrators are informed about data usage, they can more effectively review their existing capacities, identify weaknesses, and create better chart plans for improvement (Earl and Katz, 2006). In addition, solutions must be produced by taking opinions from relevant stakeholders in order to ensure data security (Balyer and Öz, 2018). It is stated that the examination of the test results for teachers will enable the development of teaching practices for the individual needs of the students (Mandinach and Honey, 2008). Accordingly, the following recommendations can be made. The recommendations determined in line with the results of the study are presented below.

- School administrators should be informed about data science and ensured that they receive the necessary training. These trainings should be given by experts in the form of workshops in practice.

- Support units should be established to assist the school administration in the collection, analysis, and interpretation of data, or assisted staff support should be provided to school administrators.

- The workload of administrators and teachers should be considered in schools, and dataoriented studies should not create too much workload.

- A common vision for data usage should be established in the decision-making process, and school administrators should lead the creation of data culture within the school.

- Parents need to be educated in terms of data usage. Parent education is of great importance for students and schools in terms of data quality, access to data and the nature of the data.

- In terms of data processing process, schools need to have appropriate software.

- In order to create school memory, it is necessary to create a common pool where administrators can record information about the school.

- In management, teachers should be cooperated on participation in the decision.

Since this study is a case study, purposive sampling method was used, and a limited number of participants could be reached. For this reason, the findings obtained from the study do not aim to generalize. Future studies can reach more generalizable results by increasing the sample size. More in-depth studies can be done by examining each of the research questions separately. 


\section{Resources}

Ahmed, Y., A. (2019). Data-based decision making in primary schools in Ethiopia, Journal of Professional Capital, and Community, 4(3), 232-259. https://doi.org/10.1108/JPCC-112018-0031

Allen, R. (2005). Using the evidence of student achievement for improvements at individual, class and school level, Using Data to Support Learning, Conference Proceedings 7-9 August 2005 Grand Hyatt Hotel, Melbourne, Victoria.

Ayeni, A., J. (2018). Principals' Decision-Making Strategies and Teachers' Productivity in Secondary Schools in Ondo Central Senatorial District of Ondo State, Nigeria, Global Journal of Management and Business Research: An Administration and Management, 18(10), 18-30.

Ayyıldız, P. (2020). Technology in clasroom management. In M. Durnalı (Ed.), Utilizing technology, knowledge, and smart systems in educational administration and leadership (pp. 42-58). Hershey, PA: IGI Global.

Balyer, A., \& Öz, Ö. (2018). Academicians' views on digital transformation in education. International Online Journal of Education and Teaching (IOJET), 5(4), 809-830.

Bowers, A.J., Shoho, A.R., Barnett, B.G (2014). Considering Use of Data by School Leders for Decision Making - An Introduction. In A.J. Bowers, A.R. Shoho, B. G. Barnett (Eds.) Using Data in Schools to Inform Leadership and Decision Making (p.1-16). Charlotte, NC: Information Age Publishing Inc.

Campbell, C., \& Levin, B. (2009). Using data to support educational improvement. Educational Assessment, Evaluation and Accountability, 21(1), 47-65.

Carlson, D., Borman, G. D., \& Robinson, M. (2011). A multistate district-level cluster randomized trial of the impact of data-based reform on reading and mathematics achievement. Educational Evaluation and Policy Analysis, 33(3), 378-398.

Creswell, J., W. (2018). Nitel Araştırma Yöntemleri [Qualitative Research Methods], Ankara: Siyasal Bookstore

Doyle, D. P. (2003). Data-based decision-making. T. H.E. Journal, 30(10), 19-21.

Durnalı, M. (2020). Yönetsel İslevler, Yönetme Sanatı, Lider Yöneticinin El Kitabı [Administrative Functions, Art of Management] (Ed. M. Özdemir), Ankara: An1 Publishing

Earl, L., \& Katz, S. (2006). Leading schools in a data rich world. Thousand Oaks, CA: Corwin Press.

Gobble, M., M. (2018). Digitalization, Digitization, and Innovation, Research-Technology Management, 61(4), 56-59, DOI: 10.1080/08956308.2018.1471280

Hough, H., Byun, E. \& Mulfinger, L. (2018). Using Data for Improvement: Learning from the CORE Data Collaborative, Technical Report, Stanford University.

Huffman, D. \& Kalnin, J. (2003). Collaborative inquiry to make data-based decisions in schools. Teaching and Teacher Education, 19, 569-580.

Lai, M. K., \& Schildkamp, K. (2013). Data-based decision making: An overview. In K. Schildkamp, M. K. Lai, \& L. Earl (Eds.), Data-based decision making in education: challenges and opportunities (pp. 9-21). Dordrecht: Springer.

Leary, L., M. (2015). Assessing Organizational Data Culture to Create an Ideal Data Ecosystem, Capstone Collection, 2799. Retrieved from https://digitalcollections.sit.edu/capstones/2799

Levin, J. A., \& Datnow, A. (2012). The principal role in data-driven decision-making using case-study data to develop multi-mediator models of educational reform, School Effectiveness and School Improvement, 23(2), 179-201, doi:10.1080/09243453.2011.599394 
Lunenburg, F., C. \& Ornstein, A., C. (2013). Educational Administration: Concepts and practices (G. Arastaman, Trans.). Ankara: Nobel Publishing.

Mandinach, E. B., \& Honey, M. (Eds.) (2008). Data driven school improvement: Linking data and learning. New York: Teachers College Press.

Marsh, J., A., Pane, J., F \& Hamilton, L., S. (2006). Making Sense of Data-based Decision Making in Education, Evidence from Recent RAND Research. Retrieved from https://www.rand.org/content/dam/rand/pubs/occasional_papers/2006/RAND_OP170. pdf

Marzano, R. J., T. Waters, \& McNulty, B. A. (2005). School Leadership That Works: From Research to Results. Alexandria, VA: Association for Supervision and Curriculum Development.

Matters, G. (2006). Using Data to Support Learning in Schools Students, teachers, systems, Victoria: Acer Press.

McGill, R.J., Kennedy, K.S., \& Busse, R.T. (2016). Data-based decision making in school counseling: Utilizing multiple single-case indicators to evaluate interventions. The Practitioner Scholar: Journal of Counseling and Professional Psychology 5(1), 104121.

McNamara, J. F., \& Thompson, D. P. (1996). Teaching statistics in principal preparation: Part one. International Journal of Educational Reform, 5(3), 381-389.

Meriam, S., B. \& Tisdell, E., J. (2016). Qualitative Research, A Guide to Design and Implementation, San Francisco: Jossey-Bass.

MoNE (2019). 2023 Eğitim Vizyonu [2023 Education Vision]. Retrieved from http://2023vizyonu.meb.gov.tr/doc/2023_EGITIM_VIZYONU.pdf

New, J. (2016). Building a Data-Driven Education System in the United States. Retrieved from https://www2.datainnovation.org/2016-data-driven-education.pdf

Öz, Ö. (2020). Dijital Liderlik: Dijital Dünyada Okul Lideri Olmak [Digital Leadership: Being a School Leader in the Digital World], International Journal of Leadership Studies: Theory and Practice, 3(1), 45-57.

Özen, Z., Kartal, E., \& Emre, İ., E. (2017). Eğitimde Büyük Veri, Eğitim Teknolojileri Okumaları [Big Data in Education, Educational Technology Readings] (Eds. H. Ferhan Odabaşı, B. Akkoyunlu ve A. İşman), Ankara: TOJET

Patton, M., Q., (2015). Qualitative Research \& Evoluton Methods, (4 ${ }^{\text {th }}$ Edition), California: Sage Publications.

Picciano, A., G. (2006). Data-driven Decision-making for Effective School Leadership, Upper Saddle River, N.J.: Pearson-Merrill Prentice Hall.

Rasheed, Z. (2018). Solving Educational Piffalls with Big Data, Dell EMC Proven Professional Knowledge Sharing. Retrieved from https://education.dellemc.com/content/dam/dellemc/documents/en-us/2018KS_Rasheed-

Solving_Educational_Pitfalls_with_Big_Data.pdf

Reeves, P., I. \& Burt, W., I. (2006). Data-based Decision-making, Challenges in Data-based Decision-making: Voices from Principals, Retrieved from: https://files.eric.ed.gov/fulltext/EJ750644.pdf

Schildkamp, K. (2019). Data-based decision-making for school improvement: Research insights and gaps, Educational Research, 61(3), 257-273, DOI: 10.1080/00131881.2019.1625716

Schildkamp, K., Poortman, C., Luyten, H. \& Ebbeler, J. (2016). Factors promoting and hindering data-based decision making in schools, An International Journal of Research, Policy and Practice, 28(2), 242-258.

Simon, H., A. (1997). Administrative Behaviour, A Study of Decision-Making Processes in Administrative Organizations, New York: The Free Press. 
Skalski, A., K. \& Romero, M. (2011). Data-based Decision Making, Retrieved from: https://www.nasponline.org/Documents/Resources\%20and\%20Publications/Handouts /Families\%20and\%20Educators/Data_Use_Jan11_NASSP.PDF

Turan, H. (2019). Veriye dayalı karar verme, Veriye Dayalı Yönetim [Data-Based Decision Making, Data-Based Management] (Ed. N. Cemaloğlu) Ankara: Pegem Academy.

UNESCO, (2017). The Data Revolution in Education, Information Paper No. 39. Retrieved from http://uis.unesco.org/sites/default/files/documents/the-data-revolution-ineducation-2017-en.pdf

Van Geel, M., Keuning, T., Visscher, A. J., \& Fox, J. P. (2016). Assessing the effects of a school-wide databased decision-making intervention on student achievement growth in primary schools. American Educational Research Journal, 53(2), 360-394.

Wayman, J. C., Jimerson, J. B., \& Cho, V. (2012). Organizational considerations in establishing the Data-Informed District. School Effectiveness and School Improvement, 23, 159178.

Wayman, J., C. Midgle, S. \& Stringfield, S. (2006). Leadership for Data-Based DecisionMaking: Collaborative Educator Teams, Paper presented at the annual meeting of the American Educational Research Association, San Francisco, CA.

Wohlstetter, P., Datnow, A., \& Park, V. (2008). Creating a system for data-based decision making: Applying the principal-agent framework. School Effectiveness and School Improvement, 19(3), 239-259. http://doi:10.1080/09243450802246376

Yenel, K. (2019). Veri Kültürü Oluşturma, Veriye Dayalı Yönetim [Creating Data Culture, Data-Based Management] (Ed. N. CEMALOĞLU) (p.123-138), Ankara: Pegem Academy.

Yıldırım, A. \& Şimşek, H. (2011). Sosyal bilimlerde nitel araştırma yöntemleri, 8. baskı. [Qualitative research methods in the social sciences, 8th Ed]. Ankara: Seçkin Publ. 